have such an interest before making the referral." Does this happen in practice?

Occasions arise when doctors can provide privately services that the NHS cannot fund, but comprehensive guidelines are needed for these because of the ethical issues that they raise. In view of the changing nature of medical practice in Britain the General Medical Council should assess the effectiveness of its current recommendation and consider updating it along the lines of the American model.

PETER WILKINSON Consultant physician

Ashford Hospital,

Ashford TW15 3AA
1 Stride R. Shares in laser centre selling fast. Hospital Doctor 1992 Jan 28: 24.

2 Butler P. Stressed GP fundholders mind their own business. Health Service Journal 1992 Jan 28: 7.

Mitchell JM, Scott E. New evidence of the prevalence and scope of physician joint ventures. ЭAMA 1992;268:80-4.

4 Swedlow A, Johnson G, Smithline N, Milstein A. Increased costs and rates of use in the California workers' compensation system as a result of self-referral by physicians. $N$ Engl $\mathcal{F}$ Med 1992;327:1502-6.

5 Hillman BJ, Joseph CA, Mabry MR, Sunshine JH, Kennedy SD, Noether M. Frequency and costs of diagnostic imaging in office practice-a comparison of self-referring and radiologistreferring physicians. N Engl F Med 1990;323:1604-8.

6 Iglehart JK. The debate over physician ownership of health care facilities. $N$ Engl $f$ Med 1989;321:198-204.

7 Iglehart JK. Efforts to address the problem of physician self-referral. $N$ Engl $f$ Med 1991;325:1820-4.

8 Crane TS. The problem of physician self-referral under the Medicare and Medicaid antikickback statute. ЭAMA 1992;268:85-91.

9 Relman AS. "Self-referral"—what's at stake? N Engl I Med 1992;327:1522-4.

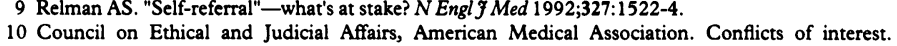
Physician ownership of medical facilities. $3 A M A$ 1992;267:2366-9.

11 General Medical Council. Professional conduct and discipline: fitness to practise. London: GMC, 1992.

\title{
Does cimetidine cause weight loss?
}

\section{Confounded expectations result in a conflict of evidence that is simply baffling}

The ideal topic for a young researcher is one in which recent publications in peer reviewed journals have come to mutually incompatible conclusions. The tyro researcher is then presented with a ready made protocol and an expectation that a replication of the study will support paper $A$ and refute $B$, or vice versa, or (more probably) reach an intermediate conclusion which throws some light on the reason for the conflict in results. Such a situation arises in this issue of the $B M F$.

Paper A, by Støa-Birketvedt on p 1091, reported the outcome in 30 overweight subjects given $200 \mathrm{mg}$ cimetidine as a suspension three times a day 30 minutes before meals, together with a fibre supplemented diet designed to supply $5 \mathrm{MJ}(1200 \mathrm{kcal}) /$ day and 30 well matched controls given the same diet but a placebo suspension. The mean (SD) weight loss over the next eight weeks was $9.5(2 \cdot 1) \mathrm{kg}$ in the treated group but only $2.2(1.3) \mathrm{kg}$ among the controls. ${ }^{1}$ Paper B, however, by Rasmussen et al on p 1093, reports a replication of the study in paper $A$, in which the authors found no significant difference in weight loss between the cimetidine and placebo groups $\left(5.7 \mathrm{~kg}\right.$ and $5.9 \mathrm{~kg}$ respectively). ${ }^{2}$ Paper B suggests that the results in A may have arisen because the subjects were not really blind to the medication taken: this may be so, but it does not resolve the problem. A mean loss of $9.5 \mathrm{~kg}$ in eight weeks is a remarkably good result, and if such weight loss could be achieved by simply telling patients they were on cimetidine that would be a therapeutic triumph.

In this situation an experienced editor may suspect that there is something wrong with the experimental data, but $\mathrm{Dr}$ Støa-Birketvedt has been commendably frank and generous in making the raw data available for examination. (The data and the patients have also been re-examined by a committee at Oslo University and confirmed to be accurate.) The results are correctly calculated and do not arise as a result of selective attrition. Papers about the treatment of obesity often fail to take account of the fact that the mean weight given for a group of patients at different points in time may refer to an ever diminishing cohort. As less successful weight losers drop out there is a false appearance of continuing weight loss in the group. Paper A started and finished with 30 patients in each group, so selective attrition cannot explain these findings.

The individual data on which paper $A$ is based show a remarkable uniformity of weight loss between individuals in each treatment group and also within individuals from week to week. Both features are hard to explain. Among groups of overweight people weight loss is usually more rapid in the first week of dieting than subsequently, probably because naive dieters lose glycogen stores with associated water first during the dieting period, and more energy dense fatty tissue later. ${ }^{3}$ This effect is seen in the results of paper B, but not paper A, in which the mean weight loss was the same in the first two weeks of cimetidine as in the last two weeks. Another expected effect not seen in the results of paper $A$ is that individuals with a higher initial weight show a greater weight loss than those with a lower initial weight. The mean weight loss in the five heaviest people, who initially weighed more than $90 \mathrm{~kg}$, was only $0.5 \mathrm{~kg}$ greater than that in people who initially weighed less than $70 \mathrm{~kg}$, whereas a difference of at least $2 \mathrm{~kg}$ in weight loss would be expected. Finally, the absolute weight loss among the cimetidine group in paper $\mathrm{A}$ is surprisingly high, and that of the control group surprisingly low, while the mean $5.8 \mathrm{~kg}$ loss in eight weeks in paper B is what might be expected in well supervised subjects with an initial body mass index (weight $(\mathrm{kg}) /$ height $(\mathrm{m})^{2}$ ) of 34 and a diet designed to supply $5 \mathrm{MJ} /$ day. It remains baffling that cimetidine and placebo should have such different effects in Norway and Denmark.

JOHN GARROW

St Bartholomew's Hospital Medical College,

Rank professor of human nutrition

London EC1M 6BQ

1 Støa-Birketvedt G. Effect of cimetidine suspension on appetite and weight in overweight subjects. BMF 1993;306:1091-3.

2 Rasmussen MH, Andersen T, Breum L, Getzsche PC, Hilsted J. Cimetidine suspension as adjuvant to energy restricted diet in treating obesity. $B M \mathcal{F}$ 1993;306:1093-6.

Garrow JS, Webster JD. Effects on weight and metabolic rate of obese women of a $3.4 \mathrm{MJ}$ (800 kcal) diet. Lancet 1989;i:1429-31. 